$$
\text { CONF-841007--1 }
$$

\title{
A PROTON-RECOIL PROPORTIONAL-COUNTER ARRAY CONF-SA1007--1 FOR NEUTRON-IMAGE CONSTRUCTION
}

\author{
C.L. Fink, J.J. Eichholz, and A. DeVolpi \\ Argonne National Laboratory
}

DE84 $0117 \bumpeq 4$

The fuel-motion measurement capability of the fastneutron hodoscope has been upgraded by the addition of a 360-detector proton-recoil proportional-counter array, which detects high-energy fission neutrons. The current sensitive amplifier/discriminator module for each detector fits into a 12.7 by 12.7 by $102 \mathrm{~mm}$ package and costs less than $\$ 100$ per module. It has a 50 ns rise time, a noise level of $100 \mathrm{nA}$, and a deadtime per event of 200 ns. Provision has been provided for the independent adjustment of the input current versus discriminator voltage for each module. The new proportional-counters cost approximately $\$ 400$ each. Each detector has been tested to have the same gain versus voltage response. A space-charge model relating count-rate changes to space-charge effects has also been developed. The new detector array has been operational for approximately two years and has become the main detector system in fuel-motion analysis. It has significantly improved the linearity, stability, count-rate capability, and setup ease of the hodoscope.

\section{DISCLAIMER}

This report was prepared as an account of work sponsored by an agency of the United States Government. Neither the United States Government nor any agency thereof, nor any of their employees, makes any warranty, express or implied, or assumes any legal liability or responsibility for the accuracy, completeness, or usefulness of any information, apparatus, product, or process disclosed, or represents that its use would not infringe privately owned rights. Reference herein to any speciffe commercial product, process, or service by trade name, trademark, manufacturer, or ocherwise does not necessarily constitute or imply its endorsement, recommendation, or favoring by the United States Government or any agency thereof. The views and opinions of authors expressed herein do noi necessarily state or rffect those of the United States Government or any agency thereof. 
Summary for IEEE Nuclear Science Symposium Orlando, Florida, Oct. 31-Nov. 2, 1984

\section{A Proton-Recoil Proportional-Counter ${ }_{\star}$ Array for Neutron-Image Construction \\ C. L. Fink, J. J. Eichholz, and A. DeVolpi \\ Argonne National Laboratory}

The fast-neutron hodoscope ${ }^{1}$ system provides a time-dependent, twodimensional image of the fuel distribution located at the center of a reactor during inpile reactor safety tests. The fuel-motion image is produced by a 360-slot cross-focused steel collimator using high-energy fission neutrons ( $>200 \mathrm{keV}$ ) emitted from the fuel. (See Fig. 1.) Detection of these nautrons at the object plane of the collimator is accomplished by a 360-element array of fast-neutron detectors.

The neutron-detector system of the fast-neutron hodoscope has recently been upgraded by the addition of a proton-recoil proportional-counter array. (The original system consisted of Hornyak-button detectors coupled to photomultiplier tubes. ${ }^{2}$ ) This work describes the electronics used in the new detector array, provides an updated report on the final proton-recoil proportional-counter design first described in Ref. 3, and summarizes the operating experience gained over the last two years.

*-Worked performed under the auspices of the U.S. Dept. of Energy. 
The circuit of the current-sensitive amplifier and the associated discriminator circuit is shown in Fig. 2. Project requirements that the electronics be packaged in a $12.7-\mathrm{mm}$ wide, by $12.7-\mathrm{mm}$ thick, by $102 \mathrm{~mm}$ ?ong box, and that the total cost of the each system be less than $\$ 100$ placed limits on the final design. The current amplifier has low noise (approximately $100 \mathrm{na}$ ) to allow operation of the proportional counter at gains as low as 5. The rise time of the amplifier is approximately 50 ns and provision has been made for easy modification of the integration and differentiation time constants. The deadtime per detected event in the circuit was designed at 200 ns to allow operation of the detectors at count rates of approximately $1 \mathrm{MHz}$ with minimum deadtime correction. Arrangement has been provided for easy adjustment of the amplifier gain and zero offset of the discriminatur so that each electronic system can be adjusted to have the same input current versus discriminator voltage response. Finally, there is provision for adding a deadtime correction circuit, aithough this part of the circuit has not been implemented.

The proton-recoil proportional counter is shown in Fig. 3. It was manufactured and tested by LND, Inc. and the cost is approximately $\$ 400$ per detector for orders of 50 or more. The choice of the main features such as gas pressure, operating voltage and gain, and anode diameter is discussed in Ref. 3. Since a goal of the system design was to have identical count rate versus high-voltage response curves for each detector, a $Q A$ procedure was added in the manufacturing process to verify that each detector had the same gain versus voltage curve. Additional work has also been done on using the 
space-charge model of Ref. 3 to predict the actual nonlinear changes in the measured count rate.

The new proportional-counter array has been operational for approximately two years. During this time period it has become the principal detector system in fuel-motion analysis. A typical set of fuel-motion images is shown in Fig. 4. An example of the calculated and measured detector nonlinearity is given in Fig. 5. Typical counting rates of the system have been between 300 to $400 \mathrm{kHz}$ with a maximum of $600 \mathrm{kHz}$ in one test. No significant problems are expected in reaching counting rates of $1 \mathrm{MHz}$. The detector and electronic response have been very stable over the short time periods during tests ( 5 to $50 \mathrm{~s}$ ) and in the extended periods between (several months). In fact, the detectors are so stable that work is in progress on using the proportional-counter system to interrelate different series of measurements on the power-coupling between the reactor and the fuel pin. The efforts of obtaining similar count rate versus discriminator curves have also been successful, with the typical variation between detectors of $\pm 5 \%$. This has greatly reduced the amount of time required to setup the system prior to a test.

In conclusion, the new proton-recoil proportional-counter detector array has provided significant improvements in the linearity, stability, count-rate capability, and setup ease of the hodoscope detection system. These in turn have lead to this system becoming the main detection device in hodoscope fuel-motion analysis. In addition the fuel-motion detection capabilities of the hodoscope have been improved. 


\section{REFERENCES}

1. A. DeVolpi, et al., "Fast-neutron hodoscope at TREAT: Methods for Quantitative Determination of Fuel Dispersal, "Nuclear Technology, $\underline{56}$, 141, (1982).

2. A. DeVolpi, et al., "Fast-neutron Hodoscope at TREAT: Development and Operation," Nuclear Technology, $\underline{27}, 449$ (1975).

3. C. L. Fink, et al., "Proton-Recoil Proportional Counter Tests at TREAT," IEEE Trans. Nuc. Sci., NS-27, 833 (1980). 


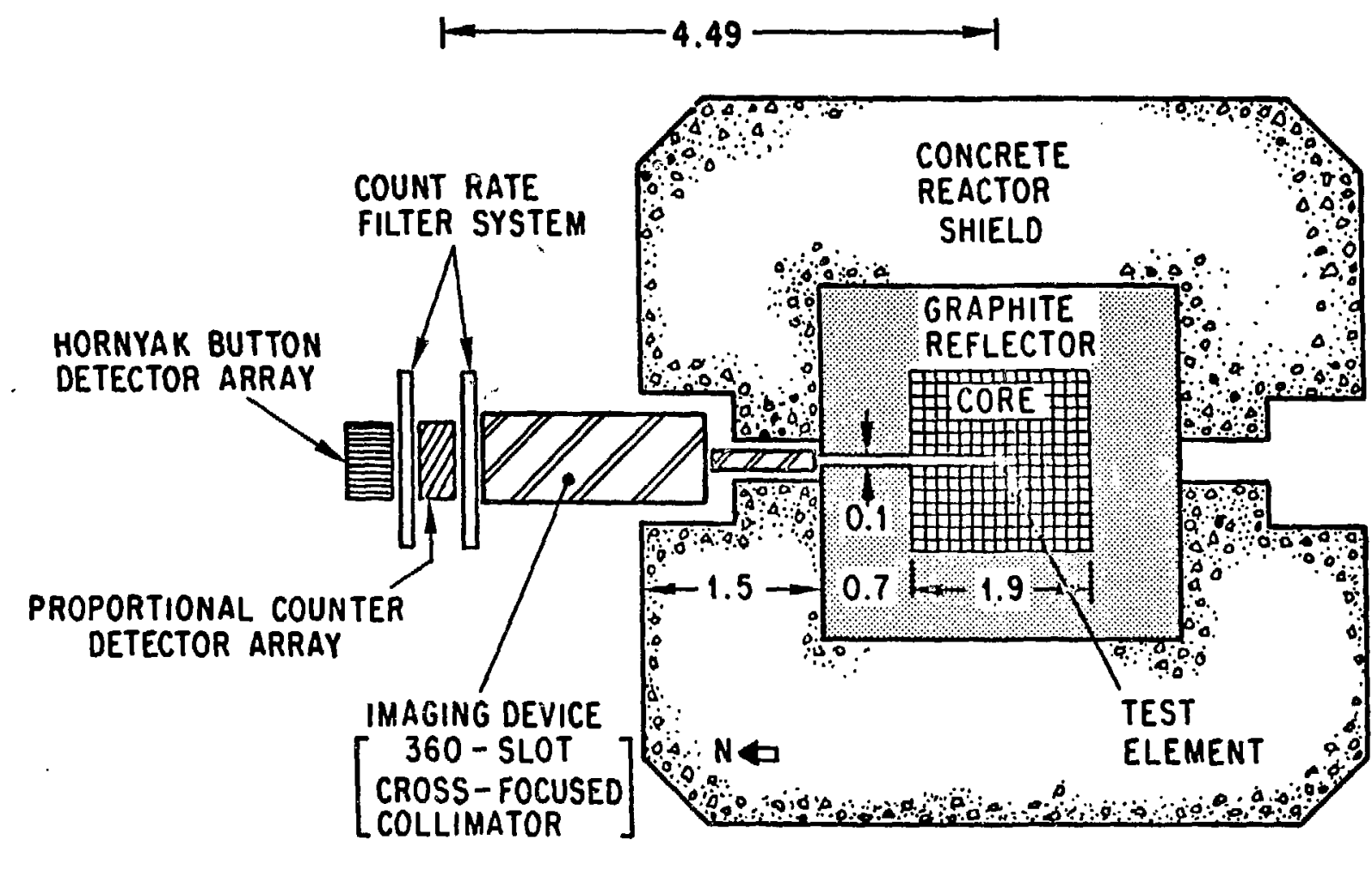

ALL DIMENSIONS IN METERS

FIg. 1. Layeut of the fast-neutron hodoscope fuel-mation detection sustem relative to the TREAT reactor core. 


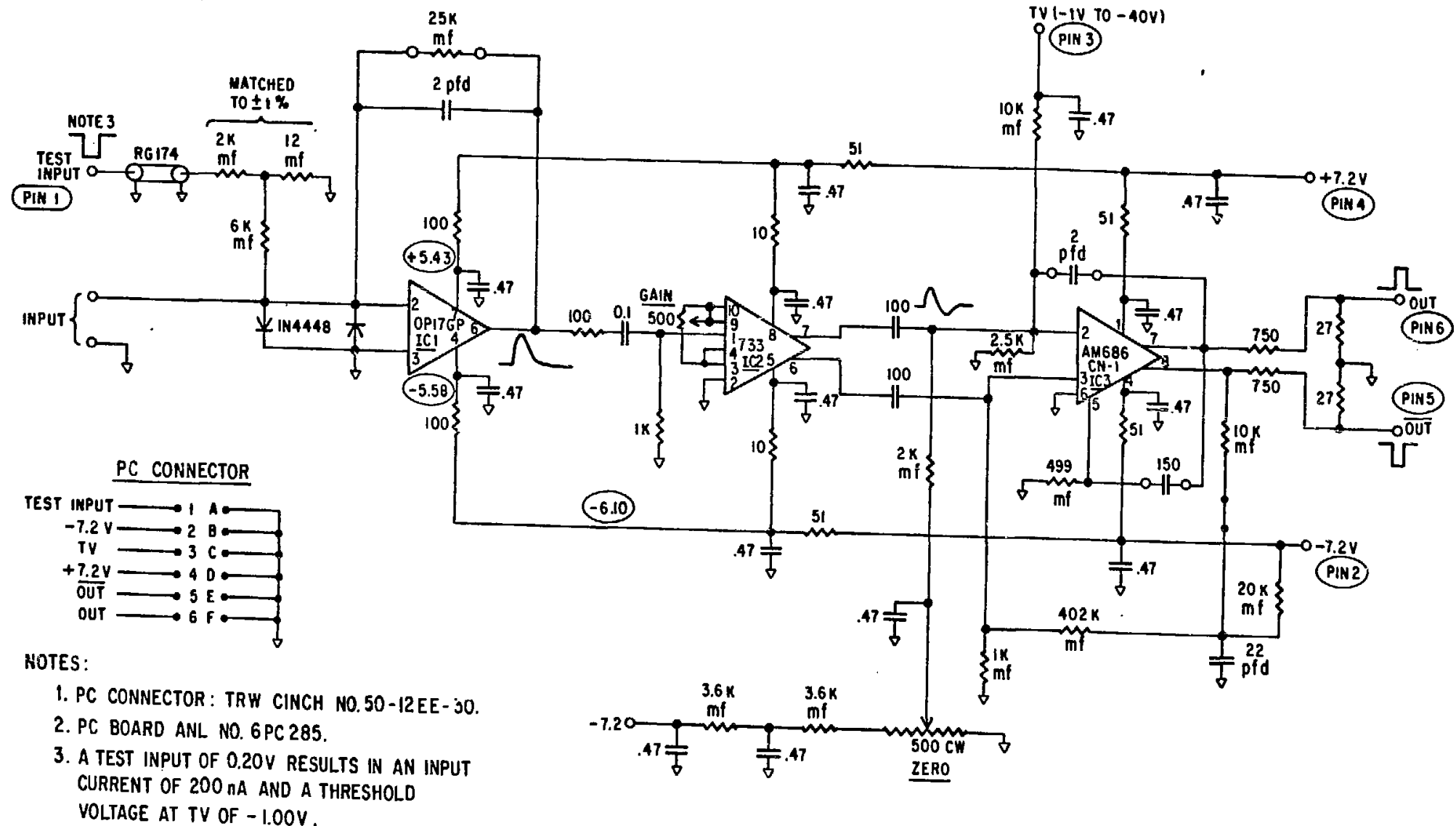

Fig. 2. Schematic of the proportional-counter amplifier and discriminator electronics. 

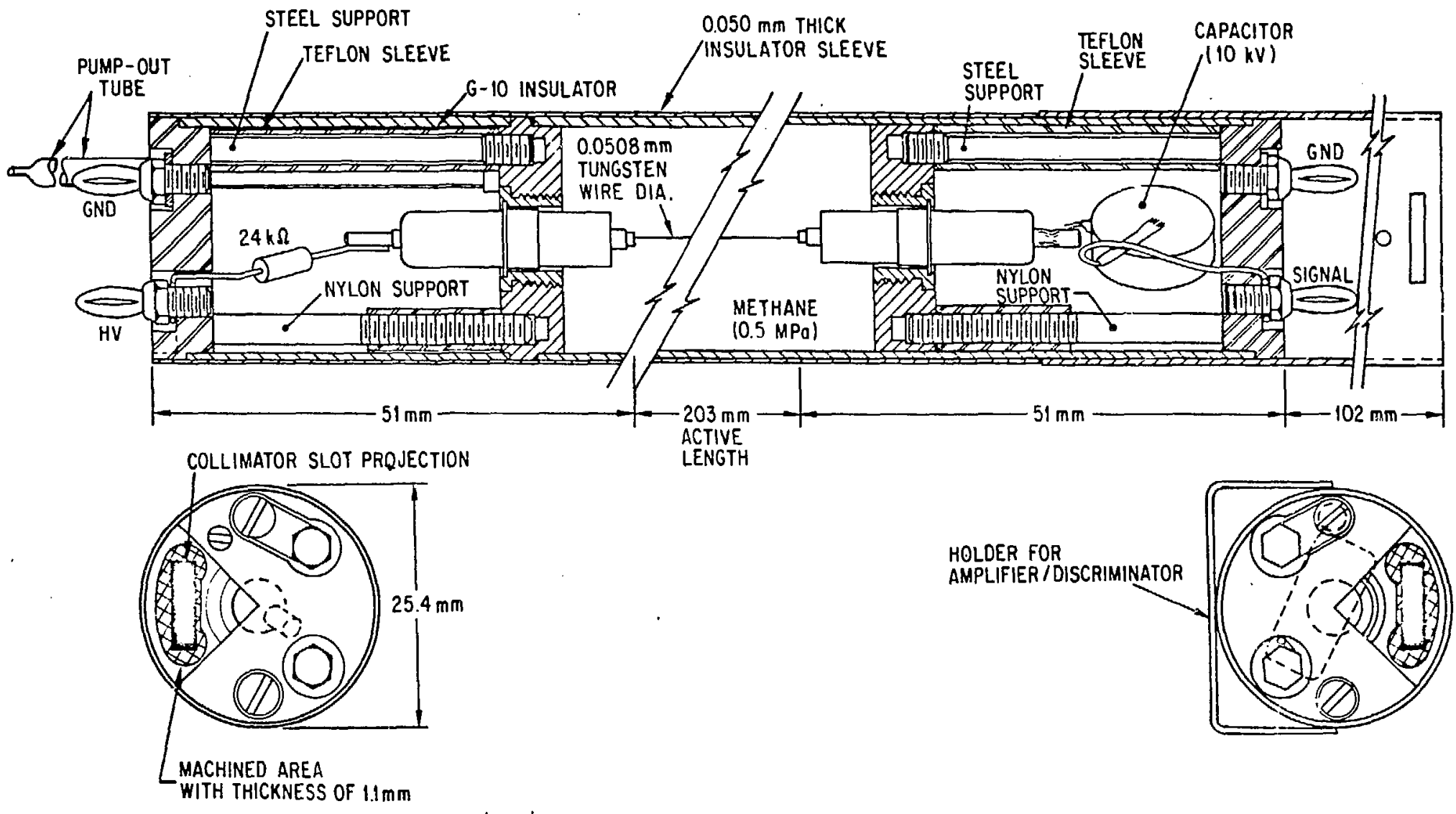

Fig. 3. Sketch of the final proportional-counter physical design. 


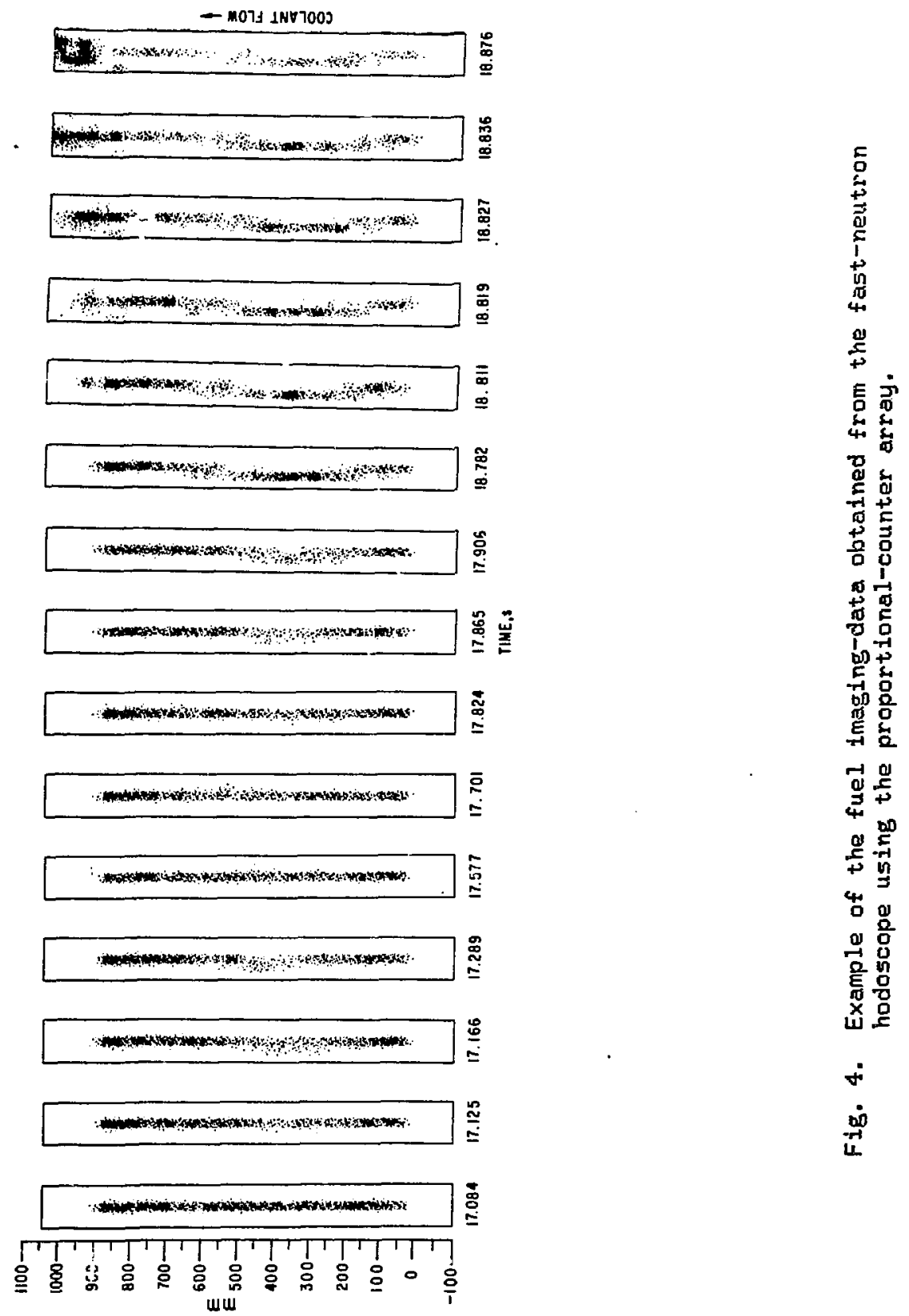




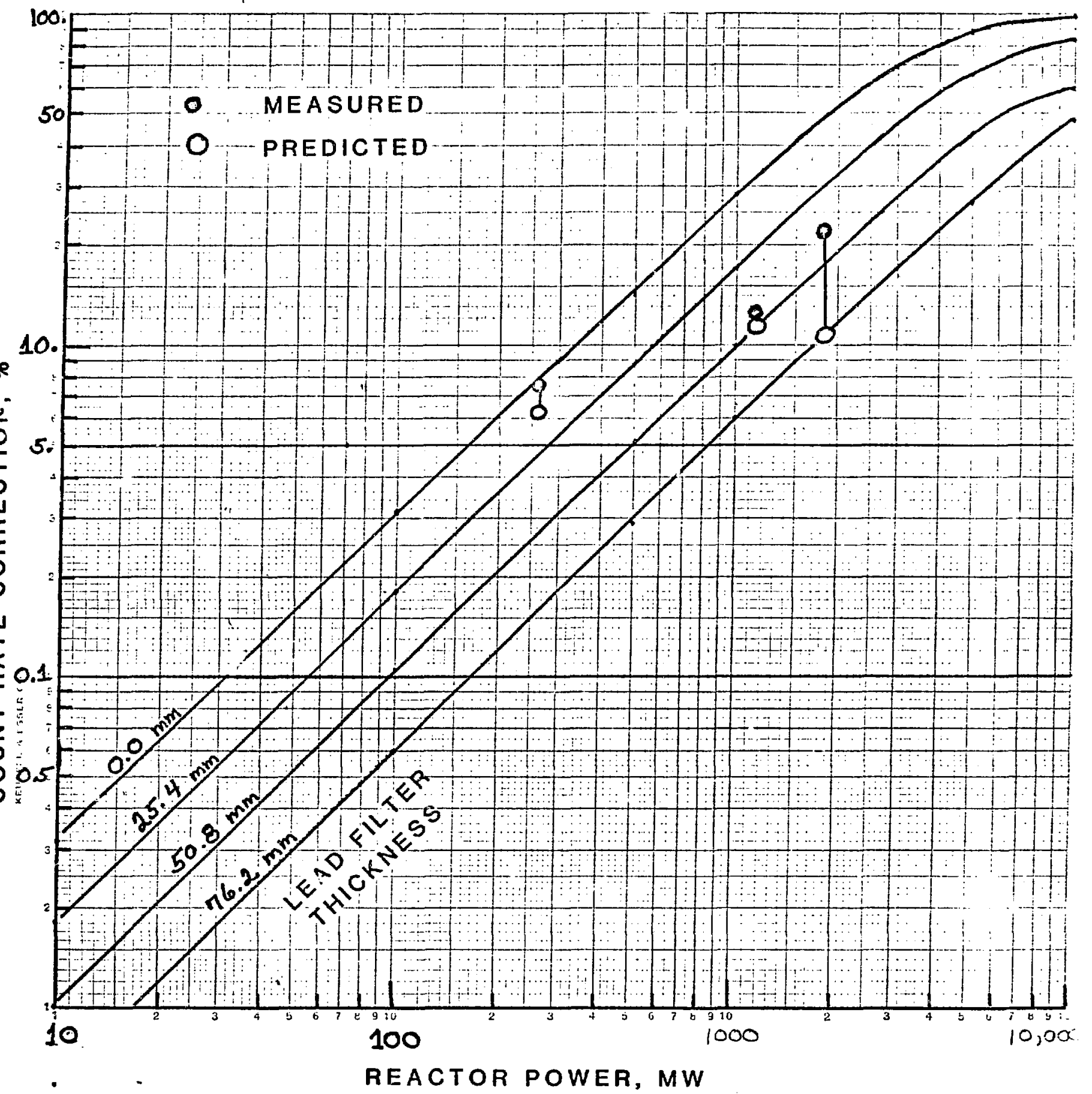

Fig. 5. Curves showing the relationship between proportional counter lincarity and reactor power. The nonlinearity is calculated using an extension of the space-charge model described in Ref. 3 . 